\title{
Restoration for the foregut surgery: bridging gaps between foregut surgery practice and academia
}

\author{
Ye-lim Shin', Shin-Hoo Park², Yeongkeun Kwon², Chang Min Lee², Sungsoo Park² \\ ${ }^{1}$ Department of Medicine, Korea University College of Medicine, Seoul, Korea \\ ${ }^{2}$ Division of Foregut Surgery, Department of Surgery, Korea University College of Medicine, Seoul, Korea
}

\begin{abstract}
Foregut surgery largely involves benign diseases, and not only malignant diseases. However, for foregut surgeons in Asia, this fact has not been extensively utilized in their clinical practice due to the high burden of gastric cancer surgery. Although the prevalence of gastroesophageal reflux disease (GERD) in Eastern Asia, including Korea, is increasing, antireflux surgery (ARS) is still a fairly rare procedure in Korea. ARS is effective as proton pump inhibitors and is cost-effective compared to continuous double-dose proton pump inhibitors in patients with severe GERD. Therefore, we should focus on ARS as a treatment option for GERD also in Asian population. Similarly, although bariatric/metabolic surgery is effective in weight reduction and diabetes mellitus (DM) remission in patients with morbid obesity or DM, bariatric/metabolic surgery is only performed in a limited number of patients. Given that the prevalence of obesity and DM is continuously increasing in Korea, bariatric/metabolic surgery should become an interest among Korean foregut surgeons and should be considered a treatment for obesity and DM. Furthermore, there are new surgical fields that can control both benign and malignant diseases. Oncometabolic surgery is a field under foregut surgery that treats both malignant and benign components of a condition, an example being the control of metabolic syndrome while performing gastric cancer surgery. Therefore, in future gastric cancer treatment, oncometabolic surgery can be applied to patients with gastric cancer accompanied by obesity or metabolic syndrome.
\end{abstract}

Keywords: Gastroesophageal reflux, Obesity, Fundoplication, Bariatric surgery

This is an Open Access article distributed under the terms of the Creative Commons Attribution Non-Commercial License (http:// creativecommons.org/licenses/by-nc/4.0/) which permits unrestricted non-commercial use, distribution, and reproduction in any medium, provided the original work is properly cited.

Received August 22, 2021

Revised October 5, 2021

Accepted October 19, 2021

Corresponding author

Sungsoo Park

Division of Foregut Surgery,

Department of Surgery, Korea

University College of Medicine, 73

Goryeodae-ro, Seongbuk-gu, Seoul

02841, Korea

Tel: $+82-2-920-6772$

Fax: +82-9-928-1631

E-mail: kugspss@korea.ac.kr

ORCID:

https://orcid.org/0000-0002-1779-8683
Copyright (c) The Korean Society of Endoscopic and Laparoscopic Surgeons.

\section{INTRODUCTION}

In the field of foregut surgery, common stomach conditions include peptic ulcer disease, stress gastritis, gastric cancer, gastroesophageal reflux disease (GERD), hiatal hernia, and morbid obesity [1]. In other words, foregut surgery largely involves benign diseases, and not only malignant diseases. However, for foregut surgeons in Asia, this knowledge has not been extensively utilized in their clinical practice due to the high burden of gastric cancer surgery. In fact, in terms of surgical performance in gastric cancer, the surgical trend over the past 10 years indi- cates a declining trend in gastrectomy rates (from $84.7 \%$ in 2011 to $46.84 \%$ in 2020 ), although bariatric surgery and antireflux surgery (ARS) rates increased from $0 \%$ to $25.95 \%$ and $0.55 \%$ to $14.58 \%$, respectively.

Gastric cancer is the fifth most common cancer globally and the second most common in Korea. While the incidence of gastric cancer is decreasing in developed countries [2,3], its incidence in Korea increased from 1999 to 2011 yet decreased thereafter [4]. In contrast, the prevalence of refractory GERD, class III obesity, and type 2 diabetes mellitus (DM) in individuals aged $\geq 30$ years in Korea has increased to $1.9 \%$ in 2016, $0.81 \%$ in 2018, and $13.8 \%$ 
in 2018, respectively [5-7].

While there is an increase in proportion of benign diseases, the same cannot be said for the actual practice proportion in Korea; that is, there is a clear gap between practice and academia. Moreover, we have observed the changing trend in disease entities from malignant to benign as well as metabolic disorders due to developments in diagnostic and treatment methods. While some of these are well-known from medical textbooks, others have been newly adopted as sophisticated entities.

Therefore, it is time to build a new foregut surgery field by reducing the gap between the academia and the practice of foregut surgery. Although subepithelial tumors and chemotherapy are foregut surgical fields, they are excluded from this study because they are already deeply embedded in current practice.

\section{TRENDS IN ANTIREFLUX SURGERY}

GERD is a disease that causes troublesome symptoms due to reflux of stomach contents; it also increases the risk of esophageal adenocarcinoma. Hence, GERD is an important foregut disease that requires intensive monitoring and treatment. The prevalence of GERD is increasing globally, with a high prevalence in North America, Australia, Oceania, and Northern Europe, yet a low prevalence in Eastern Asia [8].

Many patients who receive treatment with proton pump inhibitors (PPI) continue to exhibit symptoms [9,10]. In fact, the number of patients who receive PPI treatment for more than 12 weeks has been gradually increasing [5]. This signifies that there is an increase in the prevalence of refractory GERD. The indications for ARS are as follows: (1) failed antiacid medication, (2) wanted to receive the surgery even after successful anti-acid medication, (3) with complications of continuous acid exposure (e.g., Barrett esophagus, peptic stricture), and (4) with extraesophageal symptoms [11,12]. ARS has been shown to relieve symptoms of GERD and has been deemed effective in patients with refractory GERD $[13,14]$. In Western medicine, ARS for GERD is considered a common surgical procedure in the upper gastrointestinal field [15]; however, there is a lack of awareness of this surgical option in Korea.

Despite having lower numbers than Western Asia, the prevalence of GERD in Eastern Asia, including Korea, is still increasing $[16,17]$. In addition, the prevalence of refractory GERD in Korea has increased to $1.9 \%$ in 2016 [5]. ARS is still a fairly rare procedure in Korea, although trends do point to an increase, with 78 cases recorded in 2018 [18]. Interest in ARS has recently been growing in Korea. The Korean Anti-Reflux Surgery Study Group was established in 2010 and actively studies the procedure. According to a prospective study conducted in Korea, four aspects of GERD (i.e., heartburn, acid regurgitation, dysphagia, and atypical symptoms) improved after ARS. In addition, the GERD- related quality of life score also improved [19]. These findings suggest that ARS may be an effective method for controlling GERD symptoms in Korea. This is supported by another study, wherein $90.3 \%$ of typical symptoms and $73.5 \%$ of atypical symptoms were completely or partially resolved at 1-year follow-up. It also revealed that, in terms of surgical complications, it was not inferior to the Western trial [20].

Park et al. [21] found that ARS was much more effective and less expensive than continuous PPI double-dose administration in patients with severe GERD. The 9-year follow-up cumulative cost of ARS $(\$ 9,306.70)$ was lower than that of PPI therapy $(\$ 9,521.20)$. In other words, ARS may be more cost-effective than long-term maintenance therapy with PPI. Therefore, ARS warrants more interest from Korean foregut surgeons and should be considered a treatment for GERD.

\section{BARIATRIC/METABOLIC SURGERY}

Buchwald et al. [22] found that bariatric/metabolic surgery resulted in a $61.2 \%$ excess weight loss in patients. Other obesity comorbidities were also resolved, such as DM in $86 \%$ of patients, hypertension in $78.5 \%$, obstructive sleep apnea in $83.6 \%$, and hyperlipidemia in $70 \%$ of the patients. A total of 1,903,273 patients underwent bariatric surgery in the United States from 1993 to 2016, with an increasing annual trend observed (from 8,631 patients in 1993 to 162,969 patients in 2016) [23]. The United States National Institute of Health suggested that surgical therapy be indicated for patients with morbid obesity (with a body mass index $[\mathrm{BMI}] \geq 40 \mathrm{~kg} / \mathrm{m}^{2}$, or BMI $\geq 35 \mathrm{~kg} / \mathrm{m}^{2}$ in the presence of significant comorbidities) [22]. According to a study by Mingrone et al. [24], Roux-en-Y gastric bypass and biliopancreatic diversion were found to be more effective than medical treatment for longterm control of hyperglycemia and overall metabolic profile.

In contrast, the indications for bariatric and metabolic surgery in Korea are as follows: (1) BMI $\geq 35 \mathrm{~kg} / \mathrm{m}^{2}$ (obese class III), or (2) $\mathrm{BMI} \geq 30 \mathrm{~kg} / \mathrm{m}^{2}$ (obese class II) with comorbidities and if nonoperative treatment fails to result in weight loss [25]. The Korean indication has a lower BMI cutoff than the Western indication, and in fact, Korean patients are less obese than Western patients. According to the Korea Obesity Fact sheet, there has been an increase in prevalence of overall obesity since 2009, with class III obesity increasing to $0.81 \%$ in 2018 [6]. In the type $2 \mathrm{DM}$ patient group of Korea University Hospital, BMI of $>30 \mathrm{~kg} / \mathrm{m}^{2}$ was seen in $10.7 \%$ of the patients, which was an indication for surgery. Therefore, when performing bariatric/metabolic surgery in Korea, patients with a BMI of $30-35 \mathrm{~kg} / \mathrm{m}^{2}$ should be carefully considered.

Interest in bariatric surgery among foregut surgeons in Korea is significantly lower than that in the United States, with only 1,686 surgeries performed in 2013 [26]. This lack of interest could 
become a problem because, although the BMI of Asians is lower than that of Western counterparts, Asians have a higher percentage of subcutaneous fat [27] and prevalence of cardiovascular disease [28]. Moreover, the prevalence of obesity and type $2 \mathrm{DM}$ in Korea has gradually increased, reaching $35.7 \%$ and $13.7 \%$ in 2018, respectively $[7,29]$. Therefore, Korean foregut surgeons should not ignore bariatric surgery.

According to previous studies that focused on Koreans, bariatric surgery was found to be superior to conventional treatment in terms of weight reduction and maintenance in both shortterm and long-term follow-up [30]. In addition, bariatric surgery in patients with a BMI of $>30 \mathrm{~kg} / \mathrm{m}^{2}$ was more cost-effective than nonsurgical treatment in Koreans as well as Westerners [31]. Effects on comorbidities should also be highlighted; the type $2 \mathrm{DM}$ remission effect was noted to be better in Asians than in nonAsian populations [32].

Although the number of bariatric surgeries in Korea is still fewer than that in the West, bariatric surgery is effective in weight reduction and DM remission. Therefore, bariatric surgery should become an interest among Korean foregut surgeons and be considered a treatment for obesity and DM. Since a majority of known literature focuses on the Western population, it is recommended that active research should be done on bariatric surgeries in Korea.

\section{ONCOMETABOLIC SURGERY: A NEW SURGICAL MODALITY INCORPORATING CANCER AND METABOLIC TREATMENT}

Fundamentally, there are benign and malignant components in foregut surgery. Is there any surgical technique that can determine the effects of both? Kwon et al. [33] found that 25\% of patients who underwent conventional gastrectomy experienced DM remission 3 years after surgery. Six variables (i.e., BMI, type of gastrectomy, age, fasting plasma glucose levels, number of oral hypoglycemic agents, and insulin use/non-use) were found to predict the likelihood of DM remission [34]. Therefore, it is necessary to consider onco-bariatric surgery, which can be used to control not only gastric cancer but also metabolic syndrome and body weight, as a treatment option.

Oncometabolic surgery is a field under foregut surgery that tackles both malignant and benign components of a condition, an example being the control of metabolic syndrome while performing gastric cancer surgery. While bariatric/metabolic surgery targets obese patients, oncometabolic surgery targets gastric cancer patients regardless of their weight. Therefore, it is imperative to study patients with low BMI when approaching oncometabolic surgery. Kwon et al. [34] studied patients with low BMI and underwent radical subtotal gastrectomy. The type 2 DM remission rate at 2-year follow-up was 39.1\% in patients who underwent Billroth I reconstruction and $47.9 \%$ in the Billroth II reconstruction group. In another study, the type $2 \mathrm{DM}$ remission rate at 2- and 5-year follow-up of patients was $55.7 \%$ and $50 \%$, respectively [35]. Oncometabolic surgery was also effective in the low BMI patient group, but conversely, preoperative BMI was also a factor that influenced type $2 \mathrm{DM}$ control [35].

Therefore, in future gastric cancer treatment guidelines, oncometabolic surgery can be applied to patients with obesity or metabolic syndrome. In cases of stage I gastric cancer, sleeve gastrectomy or resectional Roux-en-Y gastric bypass may be performed instead of endoscopic resection, while long-limb Rouxen-Y reconstruction may be performed in other cases.

\section{CONCLUSION}

ARS, bariatric/metabolic surgery, and onco-bariatric surgery are treatment methods rarely performed in Korea despite being more effective than current medical treatments. Foregut surgeons will need to pay closer attention to benign diseases and their treatment, owing to their increasing prevalence. Moreover, gastric cancer guidelines should recommend a method that combines bariatric/metabolic surgery to achieve their combined effects.

\section{NOTES}

\section{Authors' contributions}

Conceptualization: YS, SP, SHP

Data curation: YS, SP, CML

Formal analysis: YS, SP, YK, CML

Funding acquisition: YS, SP

Investigation: YS, SHP, YK, CML

Methodology: YS, SP

Project administration: YS, SP, SHP, YK

Visualization: YS

Writing-original draft: YS, SP

Writing-review \& editing: All authors

All authors read and approved the final manuscript.

\section{Conflict of interest}

All authors have no conflicts of interest to declare.

\section{Funding/support}

This work was supported by the Korea Medical Device Development Fund grant funded by the Korean government (Ministry of Science and ICT, Ministry of Trade, Industry and Energy, Ministry of Health \& Welfare, Ministry of Food and Drug Safety) (Project Number: NTIS 9991007295, KMDF_PR_202012D13-02), 
and by a Korea University Grant.

\section{ORCID}

Ye-lim Shin, https://orcid.org/0000-0003-0662-946X

Shin-Hoo Park, https://orcid.org/0000-0001-9767-6100

Yeongkeun Kwon, https://orcid.org/0000-0003-4432-7403

Chang Min Lee, https://orcid.org/0000-0003-2567-5533

Sungsoo Park, https://orcid.org/0000-0002-1779-8683

\section{REFERENCES}

1. Townsend CM, Beauchamp RD, Evers BM, Mattox KL. Sabiston textbook of surgery: the biological basis of modern surgical practice. 21st ed. Philadelphia: Elsevier; 2021.

2. Global Burden of Disease Cancer Collaboration; Fitzmaurice C, Allen $\mathrm{C}$, et al. Global, regional, and national cancer incidence, mortality, years of life lost, years lived with disability, and disability-adjusted life-years for 32 cancer groups, 1990 to 2015: a systematic analysis for the global burden of disease study. JAMA Oncol 2017;3:524-548.

3. Jung KW, Won YJ, Oh CM, et al. Cancer statistics in Korea: incidence, mortality, survival, and prevalence in 2014. Cancer Res Treat 2017;49:292-305.

4. Eom BW, Jung KW, Won YJ, Yang H, Kim YW. Trends in gastric cancer incidence according to the clinicopathological characteristics in Korea, 1999-2014. Cancer Res Treat 2018;50:1343-1350.

5. Park S, Kwon JW, Park JM, Park S, Seo KW. Treatment pattern and economic burden of refractory gastroesophageal reflux disease patients in Korea. J Neurogastroenterol Motil 2020;26:281-288.

6. Nam GE, Kim YH, Han K, et al. Obesity fact sheet in Korea, 2020: prevalence of obesity by obesity class from 2009 to 2018. J Obes Metab Syndr 2021;30:141-148.

7. Jung CH, Son JW, Kang S, et al. Diabetes fact sheets in Korea, 2020: an appraisal of current status. Diabetes Metab J 2021;45:1-10.

8. Hunt R, Armstrong D, Katelaris P, et al. World Gastroenterology Organisation Global Guidelines: GERD global perspective on gastroesophageal reflux disease. J Clin Gastroenterol 2017;51:467-478.

9. Park HJ, Park SH, Shim KN, et al. The prevalence and clinical features of non-responsive gastroesophageal reflux disease to practical proton pump inhibitor dose in Korea: a multicenter study. Korean J Gastroenterol 2016;68:16-22.

10. El-Serag H, Becher A, Jones R. Systematic review: persistent reflux symptoms on proton pump inhibitor therapy in primary care and community studies. Aliment Pharmacol Ther 2010;32:720-737.

11. Stefanidis D, Hope WW, Kohn GP, et al. Guidelines for surgical treatment of gastroesophageal reflux disease. Surg Endosc 2010;24:26472669.

12. Seo HS, Choi M, Son SY, Kim MG, Han DS, Lee HH. Evidence-based practice guideline for surgical treatment of gastroesophageal reflux disease 2018. J Gastric Cancer 2018;18:313-327.
13. Dallemagne B, Weerts J, Markiewicz S, et al. Clinical results of laparoscopic fundoplication at ten years after surgery. Surg Endosc 2006; 20:159-165.

14. Frazzoni M, Piccoli M, Conigliaro R, Manta R, Frazzoni L, Melotti G. Refractory gastroesophageal reflux disease as diagnosed by impedance-pH monitoring can be cured by laparoscopic fundoplication. Surg Endosc 2013;27:2940-2946.

15. Wang YR, Dempsey DT, Richter JE. Trends and perioperative outcomes of inpatient antireflux surgery in the United States, 1993-2006. Dis Esophagus 2011;24:215-223.

16. El-Serag HB, Sweet S, Winchester CC, Dent J. Update on the epidemiology of gastro-oesophageal reflux disease: a systematic review. Gut 2014;63:871-880.

17. Fock KM, Talley N, Goh KL, et al. Asia-Pacific consensus on the management of gastro-oesophageal reflux disease: an update focusing on refractory reflux disease and Barrett's oesophagus. Gut 2016;65: 1402-1415.

18. Kim MS, Oh Y, Lee JH, et al. Trends in laparoscopic anti-reflux surgery: a Korea nationwide study. Surg Endosc 2021;35:4241-4250.

19. Park S, Park JM, Kim JJ, et al. Multicenter prospective study of laparoscopic nissen fundoplication for gastroesophageal reflux disease in Korea. J Neurogastroenterol Motil 2019;25:394-402.

20. Katz PO, Gerson LB, Vela MF. Guidelines for the diagnosis and management of gastroesophageal reflux disease. Am J Gastroenterol 2013; 108:308-328.

21. Park S, Park S, Park JM, et al. Anti-reflux surgery versus proton pump inhibitors for severe gastroesophageal reflux disease: a costeffectiveness study in Korea. J Neurogastroenterol Motil 2020;26:215223.

22. Buchwald H, Avidor Y, Braunwald E, et al. Bariatric surgery: a systematic review and meta-analysis. JAMA 2004;292:1724-1737.

23. Campos GM, Khoraki J, Browning MG, Pessoa BM, Mazzini GS, Wolfe L. Changes in utilization of bariatric surgery in the United States from 1993 to 2016. Ann Surg 2020;271:201-209.

24. Mingrone G, Panunzi S, De Gaetano A, et al. Bariatric-metabolic surgery versus conventional medical treatment in obese patients with type 2 diabetes: 5 year follow-up of an open-label, single-centre, randomised controlled trial. Lancet 2015;386:964-973.

25. Seo MH, Lee WY, Kim SS, et al. 2018 Korean Society for the Study of Obesity guideline for the management of obesity in Korea. J Obes Metab Syndr 2019;28:40-45.

26. Choi YB. Current status of bariatric and metabolic surgery in Korea. Endocrinol Metab (Seoul) 2016;31:525-532.

27. Wang J, Thornton JC, Russell M, Burastero S, Heymsfield S, Pierson RN Jr. Asians have lower body mass index (BMI) but higher percent body fat than do whites: comparisons of anthropometric measurements. Am J Clin Nutr 1994;60:23-28.

28. Deurenberg-Yap M, Yian TB, Kai CS, Deurenberg P, VAN Staveren WA. Manifestation of cardiovascular risk factors at low levels of body mass index and waist-to-hip ratio in Singaporean Chinese. Asia 
Pac J Clin Nutr 1999;8:177-183.

29. Nam GE, Kim YH, Han K, et al. Obesity fact sheet in Korea, 2019: prevalence of obesity and abdominal obesity from 2009 to 2018 and social factors. J Obes Metab Syndr 2020;29:124-132.

30. Park JY, Heo Y, Kim YJ, et al. Long-term effect of bariatric surgery versus conventional therapy in obese Korean patients: a multicenter retrospective cohort study. Ann Surg Treat Res 2019;96:283-289.

31. An S, Park HY, Oh SH, et al. Cost-effectiveness of bariatric surgery for people with morbid obesity in South Korea. Obes Surg 2020;30: 256-266.

32. Kim JH, Pyo JS, Cho WJ, Kim SY. The effects of bariatric surgery on type 2 diabetes in Asian populations: a meta-analysis of randomized controlled trials. Obes Surg 2020;30:910-923.
33. Kwon Y, Kwon JW, Kim D, et al. Predictors of remission and relapse of diabetes after conventional gastrectomy for gastric cancer: nationwide population-based cohort study. J Am Coll Surg 2021;232:973981.

34. Kwon Y, Abdemur A, Lo Menzo E, Park S, Szomstein S, Rosenthal RJ. The foregut theory as a possible mechanism of action for the remission of type 2 diabetes in low body mass index patients undergoing subtotal gastrectomy for gastric cancer. Surg Obes Relat Dis 2014; 10:235-242.

35. Lee TH, Lee CM, Park S, et al. Long-term follow-up for type 2 diabetes mellitus after gastrectomy in non-morbidly obese patients with gastric cancer: the legitimacy of onco-metabolic surgery. J Gastric Cancer 2017;17:283-294. 